\title{
Interprofessional simulation-based education enhances student knowledge of health professional roles and care of patients with tracheostomies and Passy-Muir ${ }^{\mathbb{B}}$ Valves
}

Julie M. Estis ${ }^{1}$, Alison B. Rudd ${ }^{* 2}$, Bill Pruitt ${ }^{3}$, Theresa Wright ${ }^{2}$

${ }^{1}$ Department of Speech Pathology \& Audiology, University of South Alabama, Mobile, Alabama, United States

${ }^{2}$ College of Nursing, University of South Alabama, Mobile, Alabama, United States

${ }^{3}$ Department of Cardiorespiratory Care, University of South Alabama, Mobile, Alabama, United States

Received: December 2, 2014

DOI: $10.5430 /$ jnep.v5n6p123
Accepted: February 8, $2015 \quad$ Online Published: April 27, 2015

URL: http://dx.doi.org/10.5430/jnep.v5n6p123

\begin{abstract}
An interprofessional simulation-based education activity involving speech language pathology, cardiorespiratory care, and nursing students was integrated into existing curriculum by an interprofessional faculty team. Students were presented with a realistic acute care environment containing a high-fidelity simulator as the patient and standardized patient as the family member. Small groups comprised of students from each discipline (nursing $n=60$, speech language pathologists $n=17$, respiratory therapists $n=$ 24) worked together in an interactive simulation scenario that included evaluation of patient, tracheostomy care, and speaking valve placement, with an emphasis on interprofessional teamwork and patient communication. Based upon pretest/posttest results, including an attitudinal survey, enhanced knowledge and teamwork associated with health professional roles and responsibilities and the care of tracheostomy patients with speaking valves was found.
\end{abstract}

Key Words: Interprofessional education, Simulation, Interprofessional simulation-based education, Nursing, Respiratory therapy, Speech language pathology, Passy muir valve

\section{INTRODUCTION}

Historically, speech language pathologists (SLPs), respiratory therapists (RTs), and nurses (NURs) are trained separately and function independently. ${ }^{[1]}$ Collaboration among these disciplines is essential for optimized patient care and patient communication, particularly for management of tracheostomy patients who need Passy-Muir ${ }^{\circledR}$ Valves (PMVs). Use of PMVs in patients with a tracheostomy restores the ability to communicate by vocalization- even with patients who are receiving mechanical ventilation. In addition to physiologic benefits (e.g., improved cough, reduced risk of infection, improved swallowing, reduced risk of aspiration, decreased time to decannulate), PMVs are associated with improved quality of life, decreased level of patient fear, and improved self-advocacy in care. ${ }^{[2]}$ The Joint Commission $(2008)^{[3]}$ clearly outlines responsibilities of hospitals and caregivers to provide optimal patient communication; however, care is often focused only on physiologic needs. RTs and RNs are often unaware of communication options for tracheostomy patients. SLPs, who assess and treat com-

\footnotetext{
*Correspondence: Alison B. Rudd; Email: arudd@ southalabama.edu; Address: College of Nursing, University of South Alabama, 5721 Drive North, Mobile, United States.
} 
munication and swallowing in tracheostomy patients, rely on RTs and RNs to ensure physiologic readiness for PMV placement. ${ }^{[2]}$

Overall, interdisciplinary collaboration has positive effects in terms of health outcomes and is essential to delivering safe, quality care. ${ }^{[4]}$ Students learning in interprofessional education (IPE) settings absorb more than the content, including developing an understanding of professional roles and backgrounds, while practicing communication and conflict management. ${ }^{[5]}$ Systemic reviews of IPE reflect that it fosters positive interactions and improves attitudes; however, findings are difficult to interpret because projects are diverse, metrics for analyzing outcomes vary, and data collection is lacking. Further evidence supporting the effectiveness of IPE in health professions education is needed. ${ }^{[6]}$

Simulation-based interprofessional education (IPSE) offers an effective platform for IPE, providing students with valuable learning experiences. ${ }^{[7]}$ When learners were surveyed, most indicated a desire for more simulation-based IPE training because it reinforced realistic clinical scenarios, and it taught a great deal about how learners perform as members of the healthcare team, specifically improving communication and team work. ${ }^{[7,8]}$ Simulation has also provided a safe and effective learning environment for the enhancement of tracheostomy management skills with SLP students, a group that struggles to find clinical training opportunities for such a specific patient population. ${ }^{[9]}$

An IPE simulation involving RT, SLP, and NUR students was implemented to enhance content mastery related to the interdisciplinary care of tracheostomy patients with PMVs. The student objectives of the IPSE were:

- Understand the roles of RTs, SLPs, and RNs in caring for tracheostomy patients and placing PMVs in the acute care setting

- Explain the clinical indications and benefits of PMVs for tracheostomy patients

- Evaluate and discuss interdisciplinary collaboration and teamwork in patient care

\section{Methods}

\subsection{Sample}

Participants included 69 senior-level baccalaureate nursing students, 17 graduate-level SLP students, and 24 junior-level baccalaureate RT students. Students were chosen based upon enrollment in their respective professional curriculum and clinical skills knowledge-base. Participation was voluntary and informed consent obtained. Faculty from each group was represented in the study and took an active role in all 5 methods phases outlined below.
The nursing group $(n=69)$ included students enrolled in the adult-gerontologic nursing course. All nursing participants were enrolled in a Bachelor of Science in Nursing four-year pre-licensure track, and they were accepted into the professional component of the nursing curriculum, which is a fivesemester program. Participants were in their fourth semester of the professional nursing curriculum. Prerequisite clinical courses for the adult-gerontology course include Foundations of Professional Nursing Clinical, Psychiatric/Mental Health Clinical, and Childbearing/Child Rearing Nursing Clinical (University of South Alabama College of Nursing [USACON], 2013). ${ }^{[10]}$

The SLP group $(n=17)$ included students enrolled in a Master of Science in SLP program. The program is a two-year course of study, and participants were in their fifth and final semester. Students complete clinical courses throughout the entire program across a variety of settings. Graduatelevel SLP students, as opposed to undergraduate speech and hearing sciences students, were chosen due to enrollment in a professional program and course of study. The undergraduate speech and hearing program is foundational, and it is centered on knowledge of basic sciences material. The graduate program includes clinical application and professional expectations, similar to the SLP's nursing and RT counterparts.

The RT group $(\mathrm{n}=24)$ included students enrolled in a Bachelor of Science in Cardiorespiratory Care program. The program is a four-year course of study, and participants were in their first year of the professional component. Prior to the IPSE, students completed one clinical course entitled Cardiorespiratory Care Practicum, or CRC 342. Skills taught in CRC 342 include oxygen therapy, aerosol therapy, bronchial hygiene, introduction to positive pressure ventilation, and arterial blood gas sampling and interpretation. ${ }^{[11]}$

Students were recruited by means of the simulation being part of their coursework. Typically, simulations occur within each course using a uniprofessional model; for example, nursing would typically participate in a similar scenario independently. Faculty identified the need for an interprofessional model and collaborated. Participation in the study was voluntary, and informed consent was obtained from each student participating in the study.

Each cohort of students was selected based on prior knowledge, and the ability of that student group to care for the simulated patient. Each student's ability to have progressed in the curriculum to a certain point served as an indication of prior knowledge, therefore allowing realistic expectations of patient care. For example, nursing students were recruited from the adult-gerontology course based upon that student groups' 
ability to care for patients with tracheostomies. ${ }^{[10]}$ Nursing students from courses completed earlier in the curriculum would not be appropriate, as they were not be prepared to apply complex treatments to chronically ill patients at that point in their training. The same applied to SLP and RT students; faculty selected those student groups based on their prior knowledge and the students' curriculum progression.

\subsection{Procedure}

The study was completed in 5 key phases: pre-testing, training, simulation, debriefing, and post-testing. In the pretesting phase, participants completed an 11-item knowledgebased analysis. This instrument was created by an interprofessional team of faculty representing the three professional groups (NUR, RT, SLP) to assess knowledge before and after the interprofessional education experience. Three questions measured student knowledge of the roles of health care professionals (Questions 1, 2, 3). Four questions measured student knowledge of how to care for patients with PMV (Questions 5, 6, 8, 10). Four questions measured student knowledge of clinical indications for PMVs (Questions 4, 7, 9, 11).

For the training phase, each student viewed a 45-minute online video module created and presented by Passy-Muir ${ }^{\mathrm{R}}$, Inc., developer and manufacturer of tracheostomy \& ventilator swallowing and PMVs. The module, entitled Application of the Passy-Muir ${ }^{\mathrm{R}}$ Swallowing and Speaking Valves, allowed learners to be equally prepared on aspects of the PMV including design, clinical indications, types of valves, clinical benefits, and patient assessment. ${ }^{[12]}$

For the simulation phase, students were presented with a realistic acute care environment containing a high-fidelity simulator as the patient and a standardized patient (SP) as the family member. Students were given patient information before entering the simulation including patient name, age, gender, admitting diagnosis, and healthcare provider orders. Small groups of students from each discipline worked together in an interactive simulation scenario that included evaluation of patient, tracheostomy care, and PMV placement, with an emphasis on interprofessional teamwork and patient communication. All three professional student groups were expected to function collaboratively to carry out assessments, treatments, and general care of the patient. Students participated in the simulation in groups of four, consisting of two NUR students, one RT student, and one SLP student per group. Students interacted with the simulator and SP to provide care and patient/family education. The teams also worked together to determine roles and responsibilities of the team members.

Published by Sciedu Press
The simulator iStan ${ }^{[13]}$ served as the patient, and standardized patients ${ }^{[14]}$ served as family members.

The patient scenario of Mr. Stanley Halstead was developed collaboratively by faculty from each discipline. Participants were given the following information: "Mr. Halstead is a 65 year old construction worker foreman. He has a history of chronic obstructive pulmonary disease (COPD), 60 pack year smoker, hypertension, diabetes, and coronary artery disease. He has been admitted with COPD 5 times in the past 3 years. Home medications include Norvasc, Duoneb, Pulmicort, Brovana, and HCTZ. Mr. Halstead was admitted 3 weeks ago for emergent coronary artery bypass grafting surgery. He has had difficulty weaning from the ventilator, had a tracheostomy 2 weeks ago, and is now being considered for speaking valve placement. Mr. Halstead is receiving aerosol therapy and supplemental oxygen. His family member is at the bedside."

The scenario was chosen because it incorporates the care of each discipline specifically. In this case, nursing held the role of primary caregiver and advocate. The RT provided assessment, treatment, and care for the patient related to his respiratory disorder. The SLP provided consultation to the patient for speaking valve placement. Because of the faculty members' varied backgrounds, including care of patients similar to Mr. Halstead, the students experienced a case scenario that is both realistic and relevant to their roles as future health professionals.

After the simulation, students began the debriefing phase which was based on Standard VI of Simulation Standards of Best Practice by the International Nursing Association for Clinical Simulation and Learning. ${ }^{[15]}$ Standard VI outlines five criteria that all simulation-based learning experiences should include in order to have a session aimed at promoting reflective thinking. Students debriefed on the simulation as an interdisciplinary group in a separate classroom, specifically designed for simulation debriefing. Chairs were arranged so that students sat in their simulation team (1 SLP, 1 RT, and 2 NUR students). Faculty from each profession facilitated the discussion about challenges, pitfalls, and successes that occurred within the simulation. Students provided reflective evaluation of clinical skill performance and collaborative care. Tracheostomy T.O.M. ${ }^{\circledR}$, an anatomical model manufactured by Passy-Muir ${ }^{\circledR}$, Inc., was used for review of anatomical structures, tracheostomy care, and placement of PMV. The debrief was an opportunity for faculty to provide immediate feedback to students within a supportive climate. Up to 30 minutes was allotted for the debriefing session.

In the post-testing phase, students completed the same knowledge assessment as the pre-test. An attitudinal survey was 
administered to measure students' feelings and perceptions toward IPE and IPE using simulation. In addition, student discussion in the simulation debrief was monitored by faculty and general comments related to student attitudes and perceptions were noted and used for development of further simulation-based IPE initiatives.

\section{RESULTS}

An 11-question pretest /posttest was administered to evaluate student knowledge related to PMV placement, including clinical indications, and understanding of roles of the professions in caring for tracheostomy patients. Means and standard deviations for percent correct scores across groups for pre- and post-tests are displayed in Figure 1. A repeated-measures 2 (test) X 3 (group) ANOVA revealed a significant increase in performance from pretest to posttest $(\mathrm{F}(1,96)=69.334, p<$ $.001)$ and significant differences between groups $(\mathrm{F}(2,96)=$ $26.335, p<.001)$, with no significant interaction $(\mathrm{F}(2,96)=$ $1.338, p=.267)$. Post hoc analyses revealed no significant differences between SLP and NUR students ( $p=.104)$. SLP and NUR students performed significantly higher than RT students $(p<.001)$.

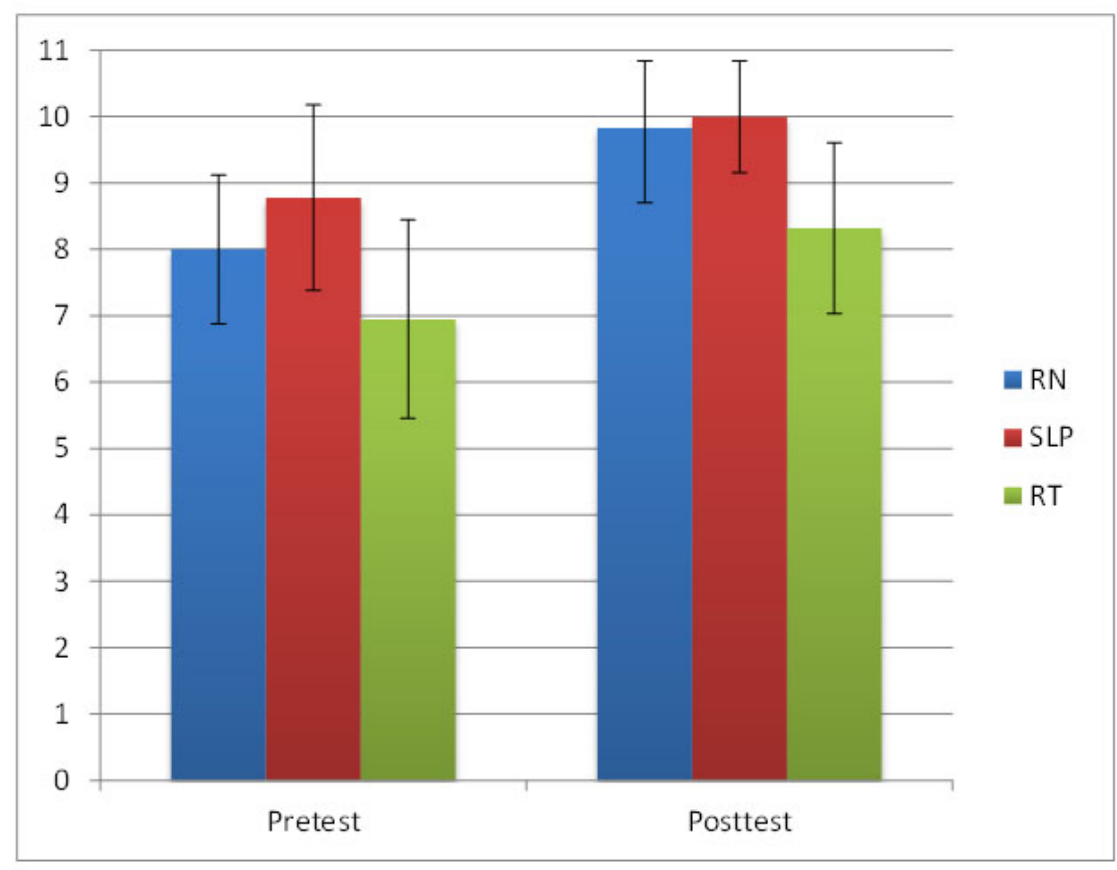

Figure 1. Student knowledge pretest/posttest means and standard deviations

Prestest/posttest means and standard deviations for percent correct scores across groups

To measure participant attitudes and perceptions of the IPE simulation experience, attitudinal survey ratings were evaluated and compared across groups. Descriptive and analytical statistics were calculated. Table 1 displays the percent responses for each level on the Likert scale (strongly agree, agree, neutral, disagree, strongly disagree). Univariate ANOVAs were calculated to measure between group differences for each question, and showed no significant differences between groups, except Question 5. SLP students rated the effectiveness of the debriefing sessions significantly lower than the NUR and RT students $(\mathrm{F}(2,96)=5.950, p=$ $.004)$.

In addition to the pre- and post-test and the Likert scale attitudinal questions, two open-ended responses were solicited. When students were asked to name one thing they learned from this experience, several themes emerged. Students most frequently indicated that they learned the importance of working as a team, roles of the professions involved, importance of communication with other health care team members, benefits of PMVs, impact of patient communication abilities, and specific skills necessary when caring for tracheostomy patients. One student stated, "I learned more about what a tracheostomy does to a patient's swallowing and breathing and what a PMV is." Another asserted, "I learned that communication and collaboration are a big key in healthcare." When students were asked what they would like to see changed about this activity in the future, they most often requested more time to train and interact with other disciplines, more preparation prior the experience, and more interaction during debriefing. One student stated, "I would have liked a little better briefing before entering room." Another said, "I 
would like more activities in the simulation. I felt it was too short." $96.4 \%$ of students indicated that they would want to participate in another interprofessional simulation activity if given the opportunity.

Table 1. Overall results of participant impressions survey

\begin{tabular}{|c|c|c|c|c|c|}
\hline & $\begin{array}{l}\text { Strongly } \\
\text { Agree }\end{array}$ & Agree & Neutral & Disagree & $\begin{array}{l}\text { Strongly } \\
\text { Disagree }\end{array}$ \\
\hline $\begin{array}{l}\text { Question 1: I feel better prepared to work with patients with } \\
\text { tracheostomy/speaking valves. }\end{array}$ & $40 \%$ & $52 \%$ & $4 \%$ & $2 \%$ & $2 \%$ \\
\hline $\begin{array}{l}\text { Question 2: I feel better prepared to work with other members of the } \\
\text { healthcare team in providing care for patients with speaking valves. }\end{array}$ & $41 \%$ & $50 \%$ & $5 \%$ & $2 \%$ & $2 \%$ \\
\hline $\begin{array}{l}\text { Question 3: I have a better understanding of healthcare team member } \\
\text { roles. }\end{array}$ & $43 \%$ & $47 \%$ & $8 \%$ & $0 \%$ & $2 \%$ \\
\hline $\begin{array}{l}\text { Question 4: I feel more comfortable communicating with healthcare } \\
\text { team members. }\end{array}$ & $36 \%$ & $55 \%$ & $7 \%$ & $0 \%$ & $2 \%$ \\
\hline Question 5: The debriefing and group discussions were valuable. & $49 \%$ & $33 \%$ & $12 \%$ & $5 \%$ & $1 \%$ \\
\hline $\begin{array}{l}\text { Question 6: The interprofessional simulation activity was more effective } \\
\text { than a traditional lecture. }\end{array}$ & $58 \%$ & $33 \%$ & $6 \%$ & $1 \%$ & $2 \%$ \\
\hline
\end{tabular}

Note. Participant impressions survey percent responses for each level on the Likert scale (strongly agree, agree, neutral, disagree, strongly disagree).

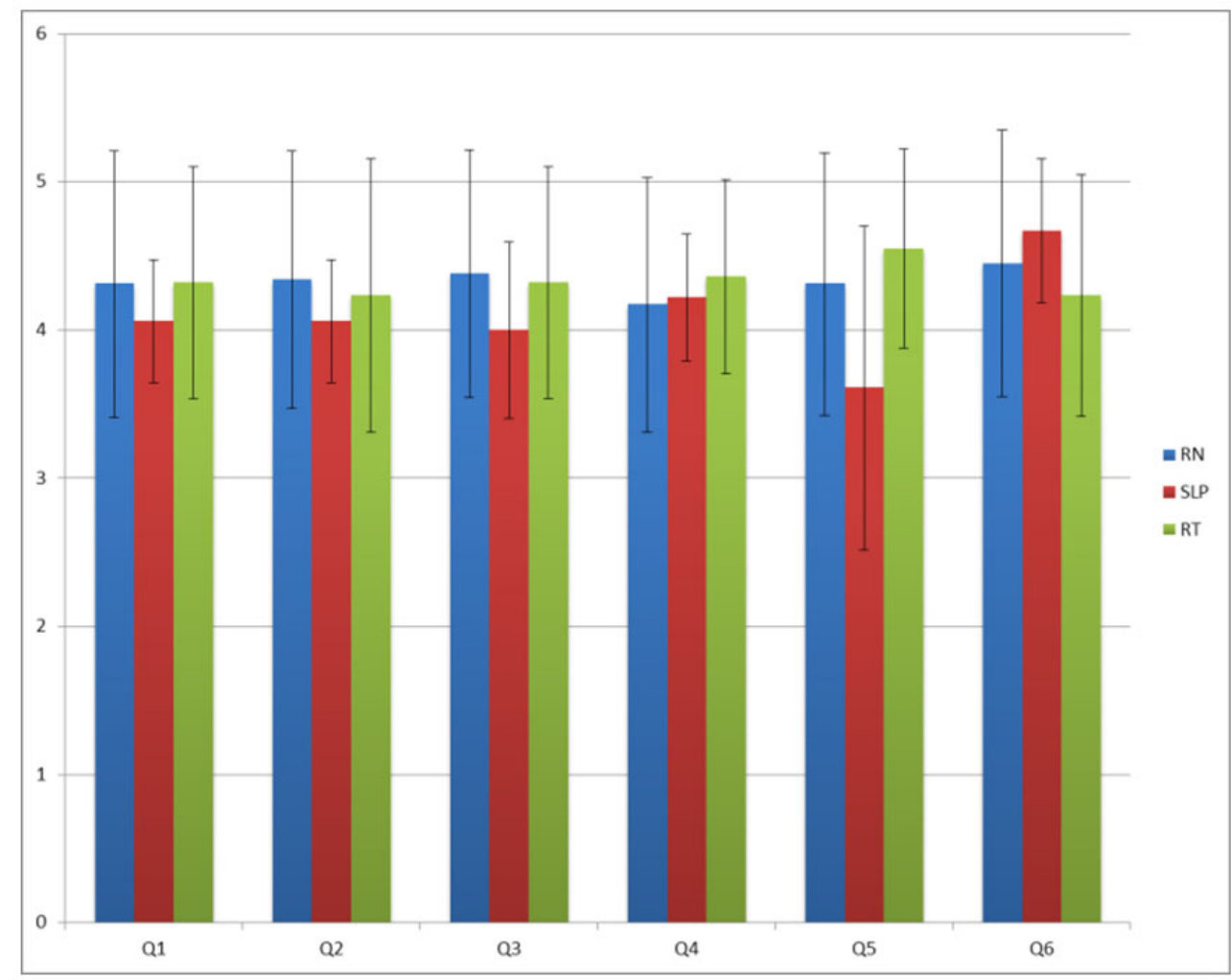

Figure 2. Results of participant impressions survey by professional group Participant Impressions Survey Means and Standard Deviations by Professional Group

\section{Discussion}

This IPSE experience provided a unique, engaging learning opportunity for NUR, SLP and RT students. Test scores showed an improvement in student knowledge of professional roles, PMVs, and clinical indications for patients with

Published by Sciedu Press tracheostomies and speaking valves. Following this activity, students were better prepared to care for patients with trachestomies and PMVs. In contrast to traditional educational methods, student participants worked together across disciplines to apply learned concepts in a realistic clinical 
scenario. Working within the multidisciplinary team as a pre-professional student enhanced readiness for collaborative practice, which is essential for positive outcomes for patients with tracheostomies and PMVs.

Attitudes and perceptions related to the IPSE and debriefing were positive. 90\% responded Agree or Strongly Agree to 6 questions related to attitudes and impressions. While this experience was challenging for students, they perceived value in this method of instruction. Participants frequently reported appreciation for increased knowledge of professional roles and the benefits and clinical indications of PMVs. Some participants indicated that the experience would be enhanced by additional pre-simulation training and more student interaction in the debriefing phase.

To expand this educational experience and further evaluate the effectiveness of IPSE, additional measurements of student outcomes have been explored. The project will be replicated with a focus on professional roles, specifically examining professional stereotypes within and between student groups. ${ }^{[16,17]}$ Also, debriefing procedures will be refined to increase student interaction. Future plans include utilization of the IPSE for practicing professionals caring for patients with tracheostomies and PMVs.

\section{Conclusion}

Interprofessional simulation-based education effectively improved RT, SLP, and NUR student knowledge of trachestomy care and PMV placement, while providing a context for practicing interprofessional teamwork, clinical skills, and patient and family education. The ethical implications of this IPSE are that students have the opportunity to train in a safe, riskfree setting that does no harm to actual patients, and through experiential learning students are better-prepared to care for patients with tracheostomies and PMV. In addition, students gained understanding of the other professional roles rather than learning and providing care independently in his or her specific role. Enhanced cooperation among care providers, as practiced during this IPSE, improves patient outcomes and yields optimal care. ${ }^{[2]}$

\section{CONFlicts of Interest Disclosure}

The authors declare that there is no conflict of interest statement.

\section{REFERENCES}

[1] Baumgartner C, Bewyer E, Bruner D. Management of communication and swallowing in intensive care: The role of the speech pathologist. AACN Advanced Critical Care. 2008 Oct; 19(4): 433 443. PMid:18981745 http://dx.doi .org/10.1097/01.AACN . 0 000340724.80280 .31

[2] de Mestral C, Iqbal S, Fong N, et al. Impact of a specialized multidisciplinary tracheostomy team on tracheostomy care in critically ill patients. Canadian Journal of Surgery. 2011 June; 54(3): 167-172 PMid:21443833 http://dx.doi.org/10.1503/cjs.043209

[3] The Joint Commission. Language Access and the Law. 2008. Available from: http://www.jointcommission.org/assets/1/6 /Lang $\% 20$ Access $\% 20$ and $\% 20$ Law $\% 20$ Jan $\% 202008 \% 20$ (17).pdf

[4] Institute of Medicine. Health professions education: A bridge to quality. Committee on the Health Professions Education Summit. (No. 0-309-08723-6). 2003. Washington, DC: National Academy Press.

[5] Clark PG. What would a theory of interprofessional education look like? Some suggestions for developing a theoretical framework for teamwork training. Journal of Interprofessional Care. 2006; 20(6): 577-589. PMid:17095437 http://dx.doi.org/10.1080/13561 820600916717

[6] Thistlethwaite J. Interprofessional education: a review of the context, learning, and the research agenda. Medical Education. $2012 \mathrm{Dec}$; 46(1): 58-70. PMid:22150197 http://dx.doi.org/10.1111/j .1365-2923.2011.04143.x

[7] Kyrkjebo J, Brattebo G, Smith-Strom H. Improving patient safety by using interprofessional simulation training in health professions education. Journal of Interprofessional Care. 2006 Oct; 20(5): 507516. PMid:17000476 http://dx.doi.org/10.1080/135618206 00918200

[8] Reese C, Jeffries PR, Engum SA. Learning together: Using simulations to develop nursing and medical student collaboration. Nursing Education Perspectives. 2010 Jan; 31(1): 33-37. PMid:20397478
[9] Ward EC, Baker SC, Wall LR, et al. Can human mannequin-based simulation provide a feasible and clinically acceptable method for training tracheostomy management skills for speech-language pathologists? American Journal of Speech-Language Pathology. 2014 Aug; 23: 421-436. PMid:24686737 http://dx.doi.org/10.1044/2 014_AJSLP-13-0050

[10] College of Nursing (USACON). Curriculum for Traditional Bachelor of Science Degree in Nursing. 2013.

[11] University of South Alabama (USA) Department of Cardiorespiratory Care. Cardiorespiratory Care Model Curriculum. 2013.

[12] Passy-Muir ${ }^{\circledR}$ Inc, Kobak J. Application of the Passy-Muir Swallowing and Speaking Valves. 2013. Available from: http://ep.passy -muir.com/educationportal/webdashboard.php

[13] CAE Healthcare. iStan. Smart. Evolved. Unplugged. 2012. Available from: http://caehealthcare.com//images/uploads/ brochures/iStan-brochure.pdf

[14] Association of Standardized Patient Educators. About ASPE. 2013. Available from: http://www .aspeducators.org/node/48

[15] International Nursing Association for Clinical Simulation and Learning. Standards of Best Practice: Simulation. 2013. Available from: http://www.inacsl.org/i4a/pages/index.cfm ?pageid $=3407$

[16] Hean S, Maclead CJ, Adams K, et al. Will opposites attract? Similarities and differences in students' perceptions of the stereotype profiles of other health and social care professional groups. Journal of Interprofessional Care. 2006a Mar; 20(2): 162-181. PMid:16608718 http://dx.doi.org/10.1080/13561820600646546

[17] Hean S, Macleod CJ, Adams K, et al. Being seen by others as we see ourselves: The congruence between the ingroup and outgroup perceptions of health and social care students. Learning in Health and Social Care. 2006b Jan; 5(1): 10-22. http: //dx .doi .org/10. $1111 / \mathrm{j} .1473-6861.2006 .00108 . \mathrm{x}$ 